\title{
The Bank of Georgia Learning Hub
}

\author{
https://doi.org/10.3991/ijac.v11i1.9367 \\ Tina Balavadze, Tatia Zhgenti \\ Bank of Georgia, Human Capital Management Department, Tbilisi, Georgia
}

\begin{abstract}
The purpose of this project is to offer Bank of Georgia employees a unique ecosystem of resources, inspiration and collaboration, as well as opportunities to increase the positive impact of work. Joining a diverse community of people will inspire, connect, and enable employees to develop their best work potential every step of the way. The goal is to develop a smart space to live the "learning" as a corporate value and promote learning as a constant process to help each other evolve and push the team toward improvement in their professional paths. Main principles: no formality, more informal relations, openness and genuine interest.
\end{abstract}

Index term-Moodle; learning culture; experience sharing; open source; transformative learning;

\section{INTRODUCTION}

The goal of the new learning concept was to recreate the learning experience for over 5000 employees, for the learning process to become a pleasant routine for selfdevelopment for the front office as well as the back office, suitable for both directions in order to master positionrelated requirements and have resources to acknowledge the latest updates on general working skills, motivation, leadership and self-awareness.

"Developing a learning culture is no longer just another fanciful idea. It is becoming more imperative for companies to cultivate learning if they wish to stay in business". Despite this trend, in Georgia you rarely see organizations driven by learning culture, especially one oriented on transformative ${ }^{2}$ learning.

Bank of Georgia managed to position itself as the market leader and one of the largest employers in the country. Rapid growth was originally very important in terms of competition, but once the position was established, the need to create something of value for internal users became apparent. Because nothing is more important for the development of an organization than employees who are satisfied and have development opportunities, we set the following goal:

Develop a knowledge and experience-sharing platform within the organization that would promote personal and professional development and growth.

In order to achieve this goal, a few milestones had to be marked and reached: a) Transformation of F2F learning experience; b) Development and promotion of eLearning

\footnotetext{
${ }^{1}$ Creating a Learning Culture for the Improvement of your Organization April 7, 2015Tala A. Nabong

https://goo.gl/CaUa2K

${ }^{2}$ Mezirow, 1991
}

culture; c) Sharing the future - building the crossfunctional teams for knowledge and experience sharing.

\section{IMPORTANCE AND TRANSFORMATION}

While development and promotion of learning culture within the organization, for both employers and employees, is quite common in Western culture, the reality of post-Soviet Georgia is entirely different: if you know something - you have more responsibilities; if you are the only one with specific knowledge within the company - you are irreplaceable; if you can get promoted anyway, why would you share knowledge, or help others? These are common stances in many Georgian organizations. Therefore, creation of the learning programs direction by the human capital management department under the slogan "helping each other to succeed" was a quite unexpected and bold statement.

Either people would go along with it and we would succeed, or all our work would remain just a bit of "fun" had by back office employees. We began taking classic change management steps ${ }^{3}$ in order to change the mindset among employees, increase employee satisfaction and decrease turnover in the long run; we believed all this would allow us to achieve increased efficiency, productivity and profit and that each employee taking part in the knowledge and experience sharing process would feel ownership and accountability for the accomplishments of the organization;

The first step taken in order to implement not just learning, but transformative learning culture, was to clearly demonstrate the necessity for change to decision-makers; it was as if they all felt something needed to change, but no one knew exactly what this "something" was; on one hand, a business knows well the results it needs to achieve and how many people it needs to achieve them, but stopping to think about how to get there is rare, as there is simply no time to do it. However, it is critical in a modern competitive environment to know what skills, and not what knowledge a person in a specific position should possess. Everyone gladly answered our questions. Our task was to figure out how to help employees achieve their full potential.

After an in-depth analysis, we created a kind of crossfunctional "coalition", identified problems and determined the main challenges and opportunities, arriving to what the optimal solution would be: see Table 1 .

The next step was to put together a team that would be able to develop a strategic vision and an initiative package as for what, how and when things needed to be changed and achieved; and all this needed to be prepared so as to ultimately build a positive attitude to learning among employees.

\footnotetext{
${ }^{3}$ John P. Kotter
} 
TABLE I.

\begin{tabular}{|c|c|}
\hline Challenges \& opportunities & Solution \\
\hline $\begin{array}{l}\text { Career paths \& horizontal } \\
\text { development }- \text { front office } \\
\text { employees cannot see prospects } \\
\text { for horizontal development, they } \\
\text { do not know what to do, what } \\
\text { knowledge or skills are needed to } \\
\text { move to a different position on the } \\
\text { same level; }\end{array}$ & $\begin{array}{l}\text { Direction routes need to be } \\
\text { created and requirements for each } \\
\text { position should be made visible; } \\
\text { what to read, what to work on in } \\
\text { order to be selected; }\end{array}$ \\
\hline $\begin{array}{l}\text { Leadership pipeline }- \text { BoG offers } \\
\text { quite a few programs for talents, } \\
\text { but by means of sending } \\
\text { employees emails and asking them } \\
\text { to reply if they are interested, } \\
\text { which causes a lack of } \\
\text { transparency and a feeling of } \\
\text { injustice - why was someone else } \\
\text { selected and not me? }\end{array}$ & $\begin{array}{l}\text { An open registration system for } \\
\text { courses }\end{array}$ \\
\hline Knowledge hoarding & $\begin{array}{l}\text { Collecting reflective experience } \\
\text { to promote experience sharing }\end{array}$ \\
\hline $\begin{array}{l}\text { Knowledge acquired during } \\
\text { trainings is subject to frequent } \\
\text { change, and employees have a } \\
\text { hard time associating separate } \\
\text { events using logic, as they tend } \\
\text { instead to memorize each piece of } \\
\text { information independently from } \\
\text { one another. }\end{array}$ & $\begin{array}{l}\text { Switch from knowledge-based } \\
\text { learning model to skill-based } \\
\text { (where applicable) }\end{array}$ \\
\hline $\begin{array}{l}\text { What we call trainings are really } \\
\text { lectures and training an employee } \\
\text { (a teller, for instance) requires a } \\
\text { very long time. }\end{array}$ & $\begin{array}{l}\text { Quick provision of various } \\
\text { targeted information; } \\
\text { Decrease of F2F training hours; } \\
\text { Creation of a micro-environment } \\
\text { which will allow employees to } \\
\text { keep up with change and } \\
\text { implement it. }\end{array}$ \\
\hline $\begin{array}{l}\text { Banking processes and procedures } \\
\text { frequently change and updating } \\
\text { employees about these changes } \\
\text { only with informational letters is } \\
\text { not effective. }\end{array}$ & $\begin{array}{l}\text { Provide information on changes } \\
\text { otherwise than only in writing } \\
\text { (which may be difficult to } \\
\text { process) }\end{array}$ \\
\hline $\begin{array}{l}\text { Up to } 3000 \text { employees are } \\
\text { required to attend several trainings } \\
\text { per year, for which the } \\
\text { organization needs to have them } \\
\text { travel to Tbilisi. }\end{array}$ & $\begin{array}{l}\text { Webinars, online tutorials, } \\
\text { tracking training attendance; }\end{array}$ \\
\hline
\end{tabular}

\section{DEVELOPING TRANSFORMATIVE LEARNING CULTURE}

For developing and supporting this idea, we decided to use a Moodle-based Learning Management System (LMS) as a knowledge-sharing platform to promote experience sharing. In our case, using an open-source solution had several distinct advantages:

- This was not just implementation of eLearning, we were tackling the challenge of implementing transformative and digital learning at the same time;

- This was a cheap and painless solution for a project with a high risk of falling through.

- We did not know how more than 5000 employees would respond to this package of changes: F2F trainings in a new format, switching to digital for a large part of technical trainings.

- To be honest, the entire process was learning by doing for us in the first place.

\section{A. Transformation of the learning process; What brought this change on?}

In this modern information world where people need to acquire various competences in order to achieve professional development and successful careers, it becomes more and more important not only to accumulate knowledge, but also to be able to process, categorize, analyze it, use it as needed etc.

- This is especially important for the newly hired employees who attend trainings as the initial stage of starting their job.

- Until now, trainings were given in a lecture-type format and were not really in line with new developments in the education field. Participants had a hard time memorizing information presented by the trainer and transferring it into practice without personal involvement and active participation.

\section{B. Teaching methodology; What changes took place?}

The teaching methodology is based on modern teaching-learning principles, which include active involvement of the participants in the training process and developing of key competences for the profession.

The following activities were offered to the participants: a) Processing and analyzing information using various strategies; b) Reviewing realistic situations and role-play using effective communication; c) Discussing open, reasoning questions; d) Preparing presentations about products and introducing them according to a sales plan; e) Joint processing of different issues and focusing on teamwork; f) Sharing the acquired experience etc.

The role of the trainer has evolved, it is now more of a guiding person who uses specific instructions and reflective questions to encourage the participants to comprehend and discuss in depth the topics envisaged in the program. By creating various practical, realistic situations, the trainer also helps the participants getting acquainted in advance with the environment they will be working in.

\section{Teaching format}

The trainings format is currently mixed; in addition to face to face trainings, there is now the learning.bog.ge distance teaching module. Participants spend part of the learning process working independently in the system.

This was made possible by creating: a) Texts and assignments for distance learning format; b) Video instructions for Core banking software; c) Digital Assignments; d) An online testing database.

Distance assignments allow:

- Focusing more during the training process on the importance and advantages of each product and ways to offer them;

- Participants to take more responsibility for their learning, to gain understanding, analyze, ask themselves questions (what have I grasped well, which parts are still unclear to me, etc.) and review them with the trainer on the next day;

- Developing digital literacy in participants;

- Saving time for the trainer, who can then use it to monitor the participants' progress and for personal professional development. 


\section{Integrated topics}

Before the introduction of renewed programs, participants took part in separate trainings about topics, service standards and sales components relevant to their position.

This approach made it difficult for the participants to put together and in practice information collected at different times from various trainings.

In order for the participants to perceive activities carried out in the frame of their position as a whole system and be able to transfer them into practice more easily, the renewed programs integrated service standards and sales components.

- Service standards are distributed throughout the training days and there is a constant focus on them;

- After each product has been covered, participants present them using the sales plan;

- Products are offered using service standards during role-play.

\section{E. Material}

- Long sentences that made it difficult to assimilate information have been divided into shorter sentences;

- The material has been adapted so as to be in line with research results on how many new words people can memorize and understand in a given context on one occasion.

- Texts have been edited, grammatical errors and sentence structuring have been corrected.

\section{F. Evaluation system}

The change in training methodology, allowing the participants to collect knowledge, develop skills and outlooks, clearly required a renewed evaluation system as well.

- Evaluation became multi-sided, with everyone responsible for the training taking part (participants, trainers, instructor, future monitor);

- Reliable and valid criteria for evaluation of the participants were developed based on the program goals and challenges;

- Achievement level features were described in detail in the assessment criteria;

- Assessment criteria and forms are known in advance to everyone interested.

The trainer and the instructor assess participants based on criteria known in advance to everyone and not on personal views and test scores. In addition to the score, they put in writing constructive feedback that is oriented on professional development of the participant.

A questionnaire was also created for assessment of the trainer and instructor by the participant, to measure their professional competence and their teaching skills.

\section{Participant}

The participant continuously receives feedback, which helps in self-evaluation and identification of one's own strong suits and areas for improvement. The participants are also involved in the process of refining the training, as they fill out reflection cards several times, focusing on topics they tackled successfully as well as the challenging parts, to which the trainer will then return.

\section{MOOdLE CUSTOMIZATION;}

Our choice fell on Moodle to be developed as a learning platform for Bank of Georgia employees. The project started in August with a 3-month timeline. On November $15^{\text {th }}$, we were ready to launch a system configured, developed and redesigned to match our needs and the employees' expectations.

The most valuable experience was the understanding that the system is for users, and while making every decision on configuration or any other issue our metric was to revisit the solution from an employee's perspective. Having restricted time and budget, this meant tradeoffs. Although the system is not really the best possible option from administration user experience perspective, it still is considered as great learning platform, which was a goal we kept in mind throughout the project.

In terms of the length of the process, considering the challenges and the involvement of the internal team: the trainers, the content managers and the system team practically achieved the impossible: a) Adaptation to requirements of a modern organization; b) Collecting reflective experience;

From the beginning we've been thinking about LMS as a platform to run and manage all learning \& development related processes. Implementation process of LMS as we perceived it would require a lot of time and financial resources. And actually it would drive us away from the main goal we have stated above. So we concentrated on creating a platform for knowledge and experience-sharing within the organization that would promote personal and professional development and growth.

In our understanding this was a platform where we could create and/or input diverse content with outstanding user experience. Which could give more than basic analytics on Employee interests, engagement and their learning outcomes. The Team's prior experience with LMS gave a hint that Moodle could have been the most cost effective alternative if having a knowledgeable implementation team.

The main difficulty was to find a vendor who had good experience in implementing Moodle as Enterprise LMS, which is an absolutely different from Educational Organization. And it is worth mentioning that the project was considered by Company as fully outsourced solution with internal product owner, thus practically no support was provided by internal IT team.

Georgian Software Implementation Market can be characterized as scarce, and even scarce when we are talking about Moodle. We found a vendor, with fairly good recommendations. Although the working process can be named as mismatch of expectations based on first impressions. The challenges can be summarized as: a) No outline for communication throughout the project; b) Wrong expectations for requirements gathering, documentation preparation/delivery and UAT cycles, that was triggered by our experience of having either internal development projects, with mostly waterfall principles or acquiring SAAS solutions, which is leveraging the functionality the way it is, without heavy configurational changes, if any. c) Mindset change for whole team:

- Changing the course content format and structure for Content team, which was an enormous work 
including: acquiring the skills necessary to go through this process and fulfilling this huge work.

- Acquiring new knowledge and skills for System Administration team and input Moodle driven changes into a daily routine seamlessly.

- Game changing experience for trainers, to perceive Moodle as their Supportive Mechanism and not a Competitor.

- Accepting the reality of becoming a main system support and developing group for a technical team, which means listening to system users, trainers, content managers, system administrators, translating their needs into technical solutions, researching the available options and discussing them with broader team, before making a final decision on solution and implementing it.

These challenges required some set of skills, beliefs and circumstances which made this project a reality:

- The environment of learning by doing

- Flexibility

- Perceiving failure as a learning opportunity and having courage to start all over again each and every time.

- Great support from the Vendor in terms of Consultancy with content structuring and creation.

- Our firm belief in a positive outcome of a Project.

As a result, we had the pilot version of the project launched in November and the project Go Live after a 3month pilot period.

\section{RESULTS}

Just a few weeks after full scale live launch of the Moodle based learning management system, we are seeing: new forms of learning for professional/position related skills and knowledge enhancement: video materials, instructions and tutorials; Structured and adapted (simplified) reading, procedures and manuals; self-check exercises that allow the participants to understand that evaluation is not a punishment measure, that the main thing is to work on one's self and skill improvement and we will provide them with material in various formats so that they can assimilate it more easily, depending on what type of learner they are; the teaching process, entirely conducted via LMS, is as follows:

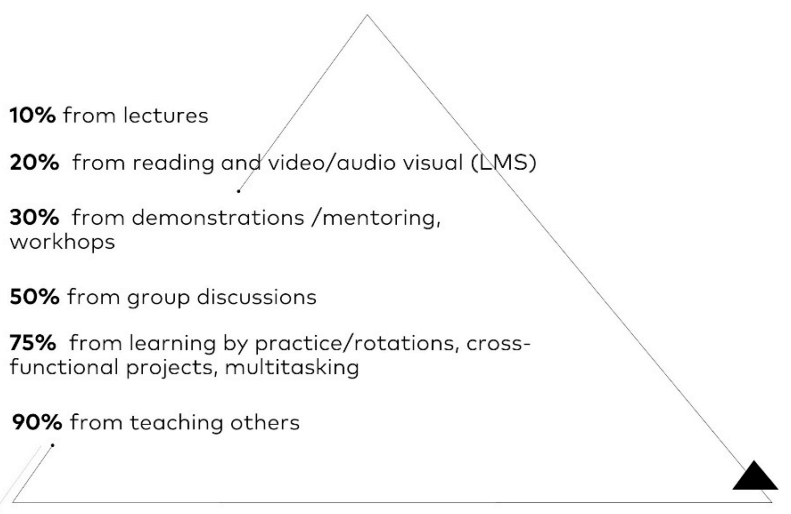

- publications (HBR / Leaders Digest/ New York Times) translated into Georgian;

- A space where you can not only learn, but also teach and become the media for learning to colleagues - any employee who considers they have the ability to teach something interesting to colleagues, whether it's project management, Excel formulas, effective email writing or other, is helped by our team in preparing a well-structured curriculum for a training; using LMS, employees register for this F2F (and later also for eCourses); with this approach, the motivation of tutor employees is very high and more and more employees wish to be involved in this process;

- Fancy interface and thought-out user experience: an attractive main page displaying headlines on every learning, training and various activities; various course structures including course content, allowing employees to select the programs they wish to be involved in; Easy and intuitive navigation, which made it easy to adapt to the new platform; Idea and experience-sharing within blogs and forums; ultimately, it is another internal communication tool that brings colleagues even closer together;

- Reporting is very important for any company; Moodle allows installing plug-ins that give very valuable analysis regarding each employee. It is possible to have grade books, which on one hand will motivate employees, and on the other hand show managers clearly the employees' progress and direction of development. Participants give detailed feedback for each program, allowing continuous improvement of the trainings.

- Needless to say, implementation of eLearning turned out to be very effective for conducting timeconsuming trainings and significantly decreased traveling and printing expenses;

- Flexible platform to evolve with company and employee development needs. As an open source platform with probably the largest and most active community, various plug-ins will guarantee the most up-to-date enhancements to the learning process and content management.

\section{CONCLUSION}

We believe the Learning Programs slogan "helping each other to succeed" can be considered precisely chosen. As a result, we strive for a reality of increased efficiency, productivity and profit, where each employee takes part in the knowledge and experience sharing process and feels ownership and accountability for the organization's accomplishments. The first steps forward this goal can definitely be considered encouraging:

- Identifying challenges \& solutions together with main stakeholders;

- Building up a team with capability to achieve the goal with positive attitude in employees;

- Implement digital tool to support the change;

We consider it to be a successful start of the exploration journey to find the best solutions to support the learning experience at Bank of Georgia. We have positive feedback from learners and their managers as a visible improvement in skills' application after the training being reported. We strive to create an environment of sharing and learning to promote and support the culture of self-development. 


\section{REFERENCES}

[1] Mezirow, Jack. (1991). Transformative Dimensions of Adult Learning.

[2] Biech (editor) (2017) ASTD Handbook: The Definitive Reference for Training \& Development 2nd Edition.

[3] Holman, Devane, Cady (2007) The Change Handbook: Group Methods for Shaping the Future.

[4] Dirken Design For How People Learn (Voices That Matter) 1st Edition.

[5] John P. Kotter Leading Change, 2012.

\section{AUTHORS}

Tina Balavadze - Learning Programs Director, Human Capital Management Department, Bank of Georgia (email: t.balavadze@,bog.ge).

Tatia Zhgenti - Head of Platforms Development Unit, Human Capital Management Department, Bank of Georgia (e-mail: tzhgenti@bog.ge).

Paper submitted 15 July 2018. Published as submitted by the authors. 